\title{
Melatonin inhibits gallbladder cancer cell migration and invasion via ERK-mediated induction of epithelial-to-mesenchymal transition
}

\author{
HONGWEI TANG ${ }^{1,2 *}$ XIAOYI SHI ${ }^{3 *}$, PENGFEI ZHU ${ }^{3}$, WENZHI GUO $^{3}$, \\ JIE $\mathrm{LI}^{3}$, BING YAN ${ }^{1,2}$ and SHUIJUN ZHANG ${ }^{1-3}$ \\ ${ }^{1}$ ZhengZhou Engineering Laboratory of Organ Transplantation Technique and Application; \\ ${ }^{2}$ Henan Engineering Technology Research Center of Organ Transplantation; ${ }^{3}$ Department of Hepatobiliary and \\ Pancreatic Surgery, The First Affiliated Hospital of Zhengzhou University, Zhengzhou, Henan 450052, P.R. China
}

Received February 9, 2021; Accepted May 19, 2021

DOI: $10.3892 / \mathrm{ol} .2021 .12870$

\begin{abstract}
Melatonin is a naturally occurring molecule secreted by the pineal gland that exhibits antitumor properties and prevents the development of human cancer. However, little is known regarding the effects of melatonin on gallbladder cancer (GBC) cells. The present study aimed to investigate the role of melatonin on the prevention of GBC cell invasion. The GBC cell line, GBC-SD, was treated with different concentrations of melatonin for different time periods, and the data indicated that melatonin markedly inhibited the invasion of GBC cells. Following treatment of GBC cells with melatonin, the protein levels of the epithelial marker, E-cadherin, significantly increased, while the expression levels of the mesenchymal markers, N-cadherin, Snail and vimentin, notably decreased. In addition, melatonin inhibited the phosphorylation of ERK1/2. Following treatment of the cells with the ERK activator, tert-Butylhydroquinone, the anti-invasive effects of melatonin were reversed by rescuing epithelial-to-mesenchymal transition in GBC cells. Taken together, these results suggest that melatonin inhibits GBC invasiveness by blocking the ERK signaling pathway. Thus, melatonin may be used as a potential novel cancer therapeutic drug for the treatment of GBC.
\end{abstract}

Correspondence to: Dr Shuijun Zhang, Department of Hepatobiliary and Pancreatic Surgery, The First Affiliated Hospital of Zhengzhou University, 1 East Jianshe Road, Zhengzhou, Henan 450052, P.R. China

E-mail: zhangshuijun@zzu.edu.cn

*Contributed equally

Key words: gallbladder cancer, melatonin, ERK signal pathway, epithelial-to-mesenchymal transition, migration and invasion

\section{Introduction}

Gallbladder cancer (GBC) is the most common malignancy of the biliary tract originating from epithelial cells of the gallbladder with a particularly high incidence (up to 7.5 per 100,000 for men and 23 per 100,000 for women) in native American and South American populations (1). It ranks sixth among malignancies of the alimentary tract and its prevalence is higher in women than in men (2). The global incidence rate of GBC has recently increased, notably in India, Eastern Europe and China (3). GBC is closely associated with genetic and environmental factors, such as chronic infection of the gallbladder, exposure to toxic compounds and heavy metals and dietary habits $(1,4)$. GBC is highly heterogeneous and invasive, which develops liver metastases due to its adjacency to the liver and lack of serosa layer (2). The diagnosis of early-stage GBC is considerably difficult and the disease develops lymphatic metastasis (5). Patients with GBC have a high mortality rate, with an overall 5-year survival rate of $\sim 5 \%$ (6). Notably, the metastatic spread of GBC is the main reason for its high morbidity (2). Although radical surgery is a preferred method for the treatment of GBC, its resection rate is low (1). Current treatment methods for GBC are ineffective, with very poor treatment efficacy (2). Thus, this cancer type is considered a serious threat to public health. Based on this evidence, it is important to identify specific and efficient drugs for the treatment of GBC.

Melatonin or N-acetyl-5-methoxytrypamine is a neurohormone predominantly synthesized and secreted by the pineal gland, with potent antioxidant, immunomodulatory and anticancer effects (7). In vivo and in vitro data have indicated that melatonin can inhibit tumor growth (8-10). However, the function and mechanism of action of melatonin vary in different types of cancer. For example, melatonin induces the inhibition of leiomyosarcoma cell proliferation and invasion, which is mediated by aerobic glycolysis (known as the Warburg effect) (11). However, in lung cancer cells, melatonin suppresses cancer metastasis by inhibiting epithelial-to-mesenchymal transition (EMT) by targeting Twist (12). In renal cell carcinoma, melatonin inhibits matrix 
metalloproteinase-9 by suppressing the AKT/MAPK pathway and the NF- $\kappa$ B DNA-binding activity (13). In human epidermal growth factor receptor 2-positive human breast cancer cells, melatonin represses metastasis by suppressing the expression of ribosomal protein S6 kinase 2 (14). Despite its extensive antimetastatic function, the effects of melatonin on GBC remain unknown.

In the present study, the antimetastatic effects of melatonin on GBC were investigated. In addition, the molecular mechanism of melatonin involved in gallbladder cancer invasion and metastasis was investigated. This hormone may be considered as a potential candidate drug in the treatment of metastatic GBC.

\section{Materials and methods}

Cell culture. The human GBC cell line, GBC-SD, was purchased from the Cell Bank of Type Culture Collection of the Chinese Academy of Sciences. The NOZ cell line was gifted by Dr Jianwen Ye, Department of Hepatobiliary and Pancreatic Surgery, The First Affiliated Hospital of Zhengzhou University (Zhengzhou, China). Cells were maintained in RPMI-1640 medium (Beijing Solarbio Science \& Technology Co., Ltd.) supplemented with $10 \%$ fetal bovine serum (FBS, Gibco; Thermo Fisher Scientific, Inc.) and $100 \mu \mathrm{g} / \mathrm{ml}$ penicillin/streptomycin, at $37^{\circ} \mathrm{C}$ with $5 \% \mathrm{CO}_{2}$ (Thermo Fisher Scientific, Inc.).

Drug treatment. Melatonin (>99\%) was purchased from MedChemExpress and dissolved in DMSO (Sigma-Aldrich; Merck KGAa). GBC-SD and NOZ cells were treated with melatonin $(0.00,0.25,0.50,1.00,2.00$ and $3.00 \mathrm{mM})$ for 24 or $48 \mathrm{~h}$, andDMSO wasusedas the control.Tert-Butylhydroquinone (tBHQ) was purchased from MedChemExpress and dissolved in DMSO. For detection of the ERK pathway, GBC-SD cells were treated with $2 \mathrm{mM}$ melatonin and $50 \mu \mathrm{M}$ tBHQ for 3 , 6 and 12 h. Cell morphology was assessed using an inverted fluorescence microscope (IX71; Olympus Corporation) (magnification x100).

Cell Counting Kit-8 (CCK-8) assay. Cell viability was assessed via the CCK-8 assay (Suzhou Yuheng Biological Technology Co., Ltd.). Briefly, GBC-SD cells were seeded into 96-well plates at a density of $5 \times 10^{3}$ cells/well. Cells were treated with different concentrations of melatonin $(0.25,0.5$, 1, 2 and $3 \mathrm{mM}$ ) for 24 and $48 \mathrm{~h}$. Melatonin was diluted in DMSO $(0.01 \%)$. The control group contained DMSO, which was adjusted according to the corresponding concentration of the highest melatonin dosage $(3 \mathrm{mM})$ to exclude the possibility of the solvent causing effects on the cells. Subsequently, $10 \mu \mathrm{l}$ CCK- 8 solution was added to each well and the plates were incubated at $37^{\circ} \mathrm{C}$ for $1 \mathrm{~h}$. The absorbance was measured at a wavelength of $450 \mathrm{~nm}$, using the Multiskan Spectrum (Varioskan LUX; Thermo Fisher Scientific, Inc.).

Wound healing assay. GBC-SD and NOZ cells were seeded into 6-well plates at a density of $1 \times 10^{6}$ cells/well and cultured at $37^{\circ} \mathrm{C}$ with $5 \% \mathrm{CO}_{2}$. Once cells reached $100 \%$ confluence, the monolayers were scratched to create a linear wound, using a $100 \mu \mathrm{l}$ pipette tip. Cells were washed three times with PBS, and RPMI-1640 medium (1\% FBS) with $3 \mathrm{mM}$ melatonin or DMSO were added to each well. Following the indicated treatment periods ( 24 or $48 \mathrm{~h}$ ), cells were observed under an inverted fluorescence microscope (IX71; Olympus Corporation) (magnification x100) and the images were captured. The proportion of wound closure was calculated according to the migration over the denuded area.

Cell invasion assay. The invasion assay was performed using Transwell chambers (Corning, Inc.). Matrigel (BD Biosciences) was diluted at a ratio of 1:10. A total of $100 \mu \mathrm{l}$ diluted Matrigel was added vertically in the upper chambers and cultured at $37^{\circ} \mathrm{C}$ with $5 \% \mathrm{CO}_{2}$ overnight. Once the cell monolayer reached $90 \%$ confluence, GBC-SD and NOZ cells were digested with trypsin. Cells were subsequently suspended in serum-free medium with or without melatonin $(2 \mathrm{mM})$ and the concentration was adjusted to $2 \times 10^{5} / \mathrm{ml}$. Subsequently $100 \mu \mathrm{l}$ cell suspension was added to the upper chamber. A total of $600 \mu \mathrm{l}$ RPMI-1640 medium with $10 \%$ FBS was plated in the lower chambers, and cells were incubated at $37^{\circ} \mathrm{C}$ for $24 \mathrm{~h}$. Non-invasive cells were removed, while invasive cells were fixed in $4 \%$ formalin at room temperature for $20 \mathrm{~min}$ and subsequently stained with $0.1 \%$ crystal violet at room temperature for $15 \mathrm{~min}$. Stained cells were counted in five randomly selected fields using a light microscope (magnification x200).

Western blotting. GBC-SD and NOZ cells were lysed with RIPA lysis buffer (Beijing Solarbio Science \& Technology Co., Ltd.) on ice for $20 \mathrm{~min}$. The cell lysate was collected and centrifuged at $13,000 \mathrm{x} \mathrm{g}$ for $15 \mathrm{~min}$. Total protein was quantified using Bicinchoninic acid (Beijing Solarbio Science \& Technology Co., Ltd.). Proteins (50 $\mu \mathrm{g} / \mathrm{lane})$ were separated by $10 \%$ SDS-PAGE. The separated proteins were subsequently transferred onto polyvinylidene fluoride membranes and blocked with non-fat milk for $3 \mathrm{~h}$ at room temperature. The membranes were incubated with primary antibodies against E-cadherin (1:5,000; cat. no. 20874-1-AP); $\mathrm{N}$-cadherin (1:5,000; cat. no. 22018-1-AP); vimentin (1:5,000; cat. no. 10366-1-AP); Snail (1:800; cat. no. 13099-1-AP); ERK (1:1,000; cat. no. AB3373); phosphorylated (p)-ERK (1:1,000; cat. no. AB3355); AKT (1:1,000; cat. no. AY0420); p-AKT (1:1,000; cat. no. AY0421); NF-кB-p65 (1:1,000; cat. no. AY5034), p-NF-кB-p65 (1:1,000; cat. no. CY6372); PI3K (1:1,000; cat. no. CY5355) and p-PI3K (1:1,000; cat. no. CY6427), overnight at $4^{\circ} \mathrm{C}$. E-cadherin, N-cadherin, Vimentin and Snail polyclonal antibodies were purchased from ProteinTech Group, Inc. ERK, p-ERK, AKT, p-AKT, NF- $\kappa$ B-p65, p-NF- $\kappa$ B-p65, PI3K and p-PI3K antibodies were purchased from Shanghai Abways Biotechnology Co., Ltd. Membranes were washed three times with TBS and Polysorbate 20, and subsequently incubated with Rabbit Anti-Goat IgG $(\mathrm{H}+\mathrm{L})$ horseradish peroxidase (HRP) (1:5,000; cat. no. AB0103; Shanghai Abways Biotechnology Co., Ltd.) for $1 \mathrm{~h}$ at room temperature. Protein bands were visualized using an ECL kit (Suzhou Xinsaimei Biotechnology Co., Ltd.). The gray levels of the protein bands were analyzed using ImageJ 1.8.0 software (National Institutes of Health) and the relative protein levels were normalized to GAPDH.

Reverse transcription-quantitative $(R T-q) P C R$. Total RNA was extracted from GBC-SD cells using TRIzol ${ }^{\circledR}$ reagent 
Table I. Primer sequences used for quantitative PCR.

\begin{tabular}{lll}
\hline Number & Name & \multicolumn{1}{c}{ Primer sequences } \\
\hline Primer 1 & h-GAPDH & F: GGAGCGAGATCCCTCCAAAAT \\
Primer 2 & h-E-Cadherin & F: GGCTGTTGTCATACTTCTCATGG \\
& & R: TCCCAGGCCCTCGACACCCGAT \\
Primer 3 & h-N-Cadherin & F: AGCCAACCTTAACTGAGGAGT \\
& & R: GGCAAGTTGATTGGAGGGATG \\
Primer 4 & h-Vimentin & F: TGCCGTTGAAGCTGCTAACTA \\
& & R: CCAGAGGGAGTGAATCCAGATTA
\end{tabular}

F, forward; R, reverse.
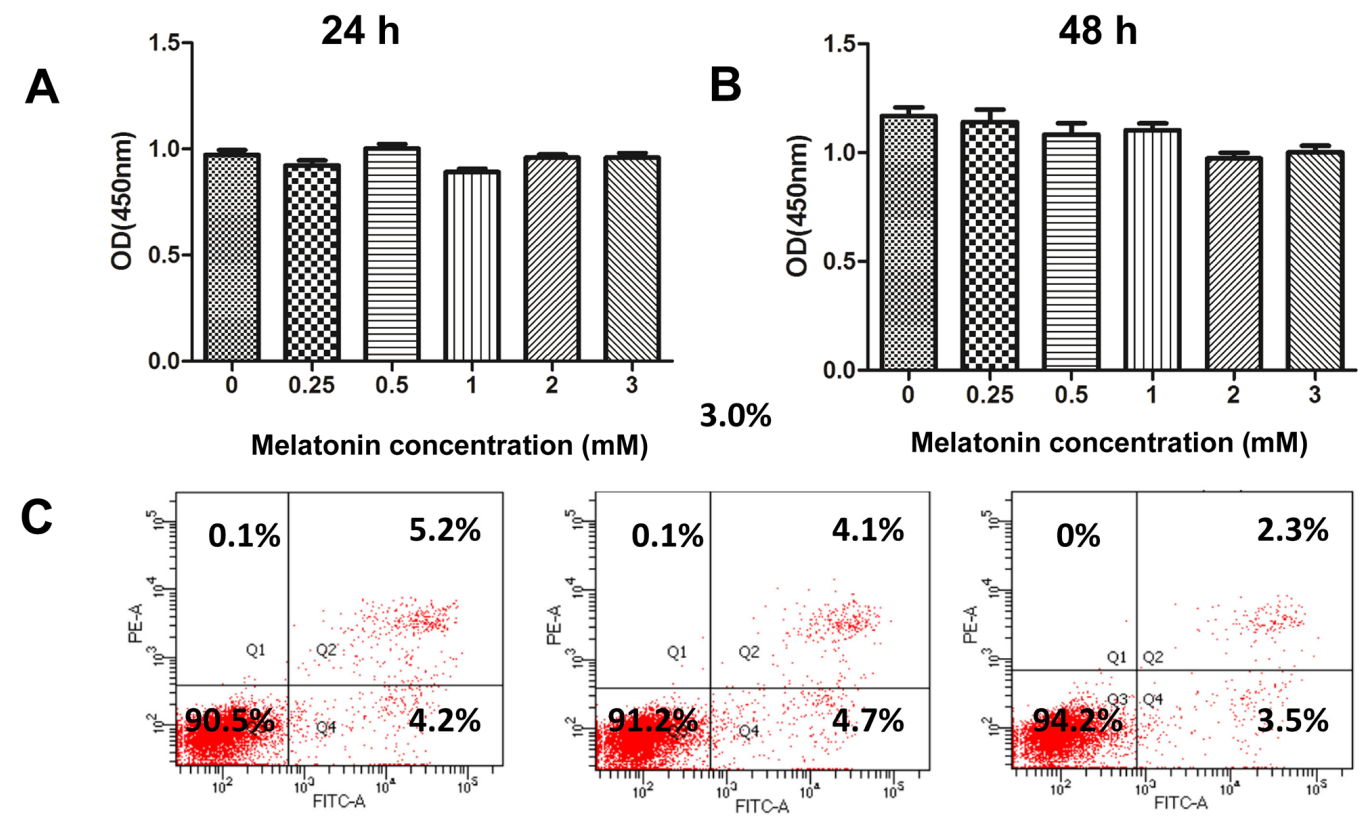

0

0.25

0.5

Melatonin concentration (mM)

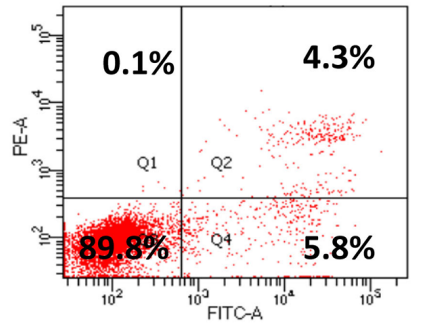

1

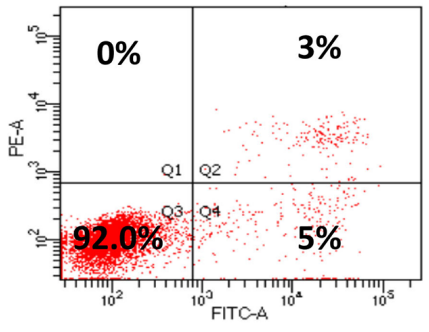

2

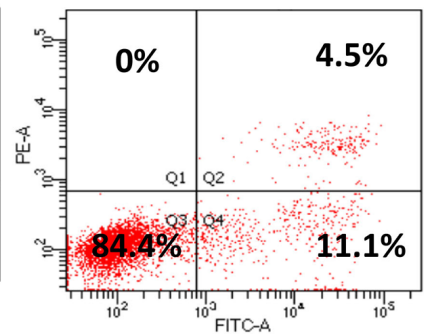

3

Melatonin concentration (mM)

Figure 1. Effect of melatonin on the viability of human GBC cells. The Cell Counting Kit- 8 assay was performed to assess the effect of melatonin on the viability of GBC cells treated with melatonin (0-3 mM) for (A) 24 or (B) $48 \mathrm{~h}$. (C) GBC cells were treated with melatonin (0-3 mM) for $48 \mathrm{~h}$ and subsequently subjected to flow cytometry to detect apoptosis. GBC, gallbladder cancer; OD, optical density.

(Gibco; Thermo Fisher Scientific, Inc.), according to the manufacturer's instruction. cDNA was synthesized using the HiScript II Reverse Transcriptase kit (Vazyme Biotech Co., Ltd.) according to the manufacturer's protocol. The reverse transcription conditions used were as follows: $25^{\circ} \mathrm{C}$ for $5 \mathrm{~min}$, $50^{\circ} \mathrm{C}$ for $15 \mathrm{~min}$ and $85^{\circ} \mathrm{C}$ for $2 \mathrm{~min}$. qPCR was subsequently performed using the PowerUp ${ }^{\mathrm{TM}}$ SYBR-Green Master mix (Applied Biosystems; Thermo Fisher Scientific, Inc.), with 

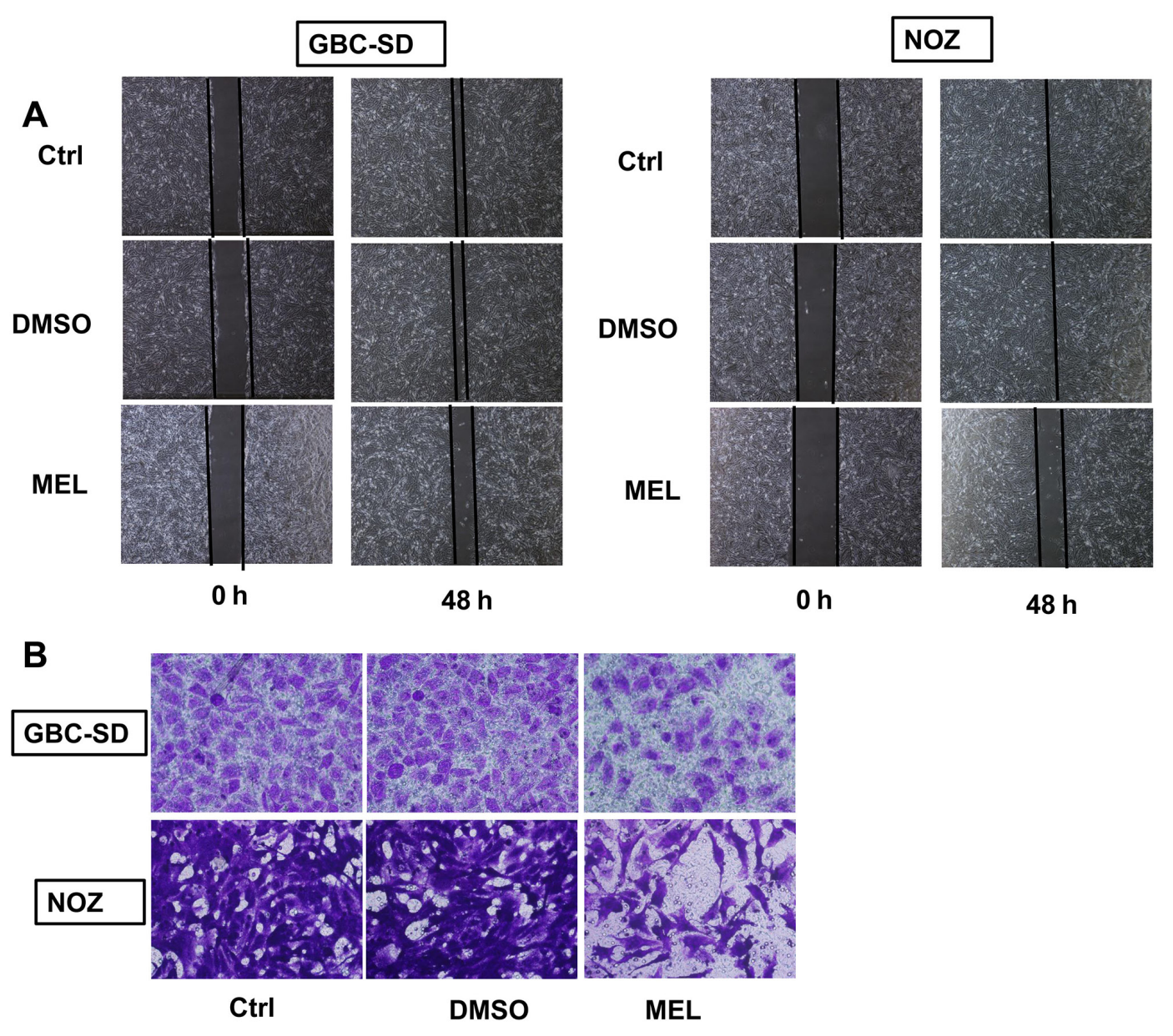

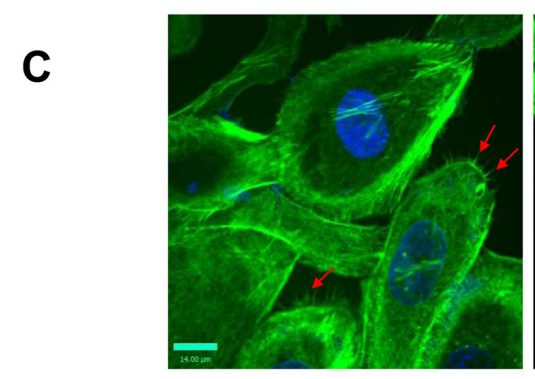

Ctrl

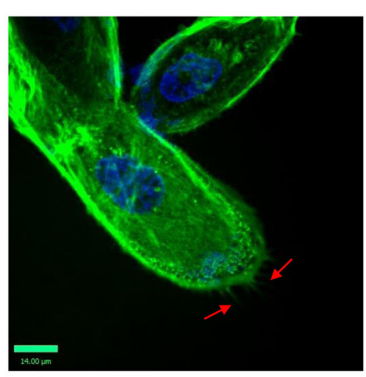

DMSO

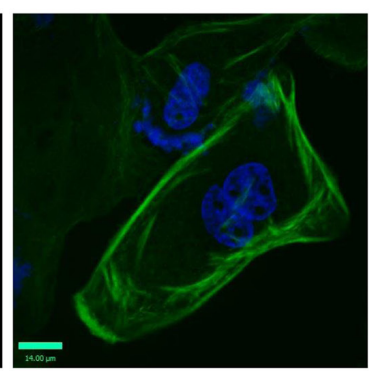

MEL

Figure 2. Antimetastatic effect of melatonin in GBC cells. (A) The wound healing assay was performed to assess cell migration (x100) following treatment with melatonin $(2 \mathrm{mM})$ for $48 \mathrm{~h}$. (B) The Transwell assay was performed to assess cell invasion (x200) following treating with melatonin (2 mM) for 48 h. (C) Fluorescence images (x400) of GBC cells stained with YF Dye Phalloidin Conjugates (F-actin) and DAPI (nuclei) following treatment with melatonin $(2 \mathrm{mM})$ for $48 \mathrm{~h}$. Red arrow indicate microfilament. GBC, gallbladder cancer; Ctrl, control; MEL, melatonin.

specific primer sequences. The thermocycling conditions used were as follows: Pre-denaturation at $95^{\circ} \mathrm{C}$ for $30 \mathrm{sec}$, denaturation at $95^{\circ} \mathrm{C}$ for $5 \mathrm{sec}$ and annealing at $59.5^{\circ} \mathrm{C}$ for $30 \mathrm{sec}$ for a total of 40 cycles. The fold change in relative mRNA levels was expressed as the relative quantification calculated by the average of the standardized gene expression levels $2^{-\Delta \Delta \mathrm{Cq}}$ (15). GAPDH was used as the housekeeping gene. The primer sequences used for qPCR are listed in Table I.

Phalloidin staining. GBC-SD cells were seeded into 24-well plates with carry sheet glass and treated with melatonin $(2 \mathrm{mM})$ for $6 \mathrm{~h}$. Cells were fixed with $4 \%$ paraformaldehyde for $15 \mathrm{~min}$ at room temperature. Cells were re-washed 3 times with PBS and YE Dye phalloidin conjugates (US Everbright) staining was performed according to the manufacturer's instructions. DAPI was used for nuclear staining at room temperature for $5 \mathrm{~min}$. The images were acquired using a laser scanning confocal microscope (Nikon A1R/A1; Nikon Corporation) (magnification $\mathrm{x} 400$ ).

Flow cytometry. The Annexin-V assay was performed to assess the detection of exposed phosphatidylserine, which provides a highly sensitive method for detecting apoptosis (16). A total of $3 \times 10^{5}$ GBC-SD cells were seeded into 6-well plates and treated with different concentrations of melatonin $(0,0.25,0.5,1,2$ and $3 \mathrm{mM}$ ) for $48 \mathrm{~h}$. The Annexin-V/PI double staining kit (BD 
A

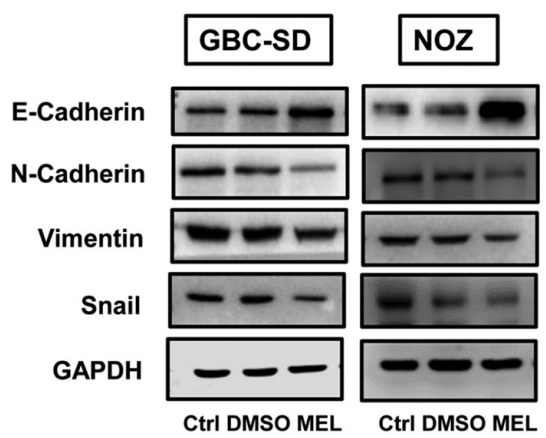

C

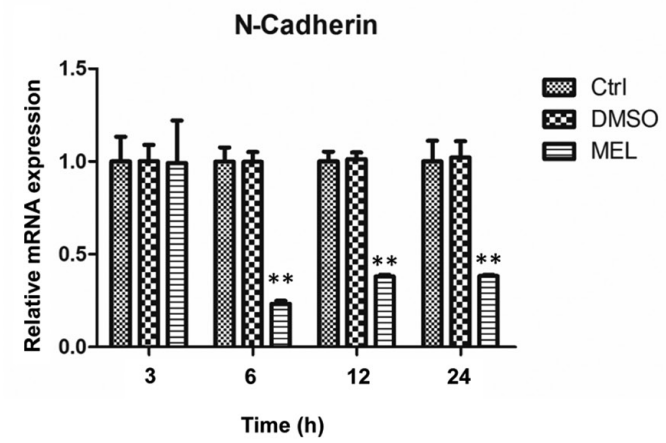

B

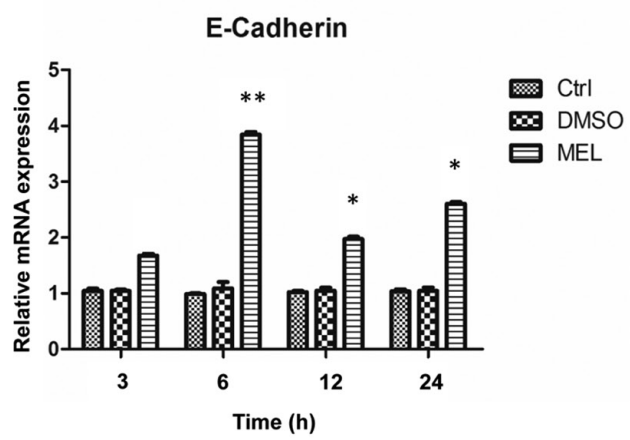

D

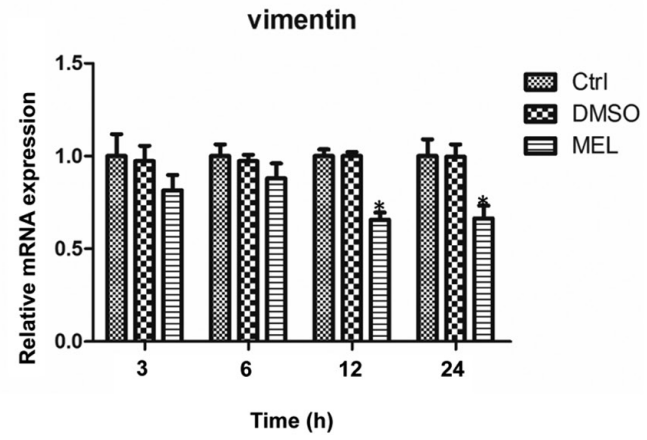

Figure 3. Melatonin regulates the epithelial-to-mesenchymal transition phenotype of GBC cells. (A) Western blot analysis was performed to detect the protein expression levels of E-cadherin, $\mathrm{N}$-cadherin, Snail and vimentin in GBC and NOZ cells following treatment with $2 \mathrm{mM}$ melatonin for $48 \mathrm{~h}$. (B-D) The $\mathrm{mRNA}$ expression levels were detected via reverse transcription-quantitative $\mathrm{PCR}$ analysis. Data are presented as the mean $\pm \mathrm{SD}$. ${ }^{*} \mathrm{P}<0.05{ }^{* * *} \mathrm{P}<0.01 \mathrm{vs}$. the control group. GBC, gallbladder cancer; Ctrl, control; MEL, melatonin.

Biosciences) was used to detect apoptotic cells, according to the manufacturer's instructions. Apoptosis cells were detected by flow cytometry (BD Canto II; BD Biosciences). Cell apoptosis was analyzed by BD FACSDiva Software v.8.0.1 (BD Biosciences). Cells that were positive for Annexin-V and negative for PI were considered viable cells, while cells that were in the early apoptotic phase were Annexin-V positive and PI negative. Cells that were non-viable or late apoptotic were Annexin-V and PI-positive.

Statistical analysis. Statistical analysis was performed using SPSS 17.0 software (SPSS Inc.). All experiments were performed in triplicate and data are presented as the mean \pm SD. Paired Student's t-test followed by the Shapiro-Wilk W test were used to compare differences between two groups, while one-way ANOVA followed by Bonferroni's test were used to compare differences between multiple groups. $\mathrm{P}<0.05$ was considered to indicate a statistically significant difference.

\section{Results}

Cytotoxicity of melatonin in GBC cells. Melatonin induces apoptosis in various human cancer cells, such as hepatocellular carcinoma, lung cancer, cholangiocarcinoma and pancreatic cancer cells (11-14). Thus, the present study initially investigated whether melatonin promotes cellular apoptosis in human GBC cells. Treatment of GBC-SD cells with melatonin $(0.25,0.5,1,2$ and $3 \mathrm{mM})$ for 24 or $48 \mathrm{~h}$ did not significantly affect cell viability, according to the CCK-8 assay (Fig. 1A and B). To further confirm the cytotoxicity of melatonin, Annexin V-FITC/PI double staining was performed to determine the induction of apoptosis via flow cytometry. The number of early and late apoptotic cells did not significantly increase following treatment with melatonin (0-2 $\mathrm{mM})$ for $48 \mathrm{~h}$ (Fig. 1C). However, the apoptotic rate of GBC-SD cells increased to $15.6 \%(4.5+11.1 \%)$ following an increase in the concentration of melatonin to $3 \mathrm{mM}$. Thus, the concentration range of melatonin (0-2 $\mathrm{mM})$ was adjusted in subsequent experiments to investigate its antimetastatic properties.

Melatonin inhibits GBC cell migration and invasion. Metastasis plays a significant role in the malignant status of GBC (2). Thus, the effects of melatonin on GBC cell invasion and migration were examined in the present study. The wound healing assay was performed to assess cell migratory, and the results demonstrated that melatonin $(2 \mathrm{mM})$ significantly inhibited the rate of wound closure compared with the control group (Fig. 2A). The effects of melatonin were also verified using Matrigel chambers. Melatonin significantly decreased the number of cells that passed through the membrane (Fig. 2B). To assess the effects of melatonin on cell movement, YF dye phalloidin conjugates were used to stain the actin filaments of GBC cells. Phalloidin is found in amanita phalloides, and can specificity bind to polymerized microfilaments (17). By binding to the polymerized microfilaments, the cyclic peptides inhibit the disintegration of the microfilaments, and destroy the dynamic balance of polymerization and depolymerization of the microfilaments (17). Treatment of GBC cells with melatonin $(2 \mathrm{mM})$ decreased the number of microfilaments compared with the control group (Fig. 2C). Taken together, these results suggest that melatonin mitigates the invasive and migratory abilities of GBC cells. 


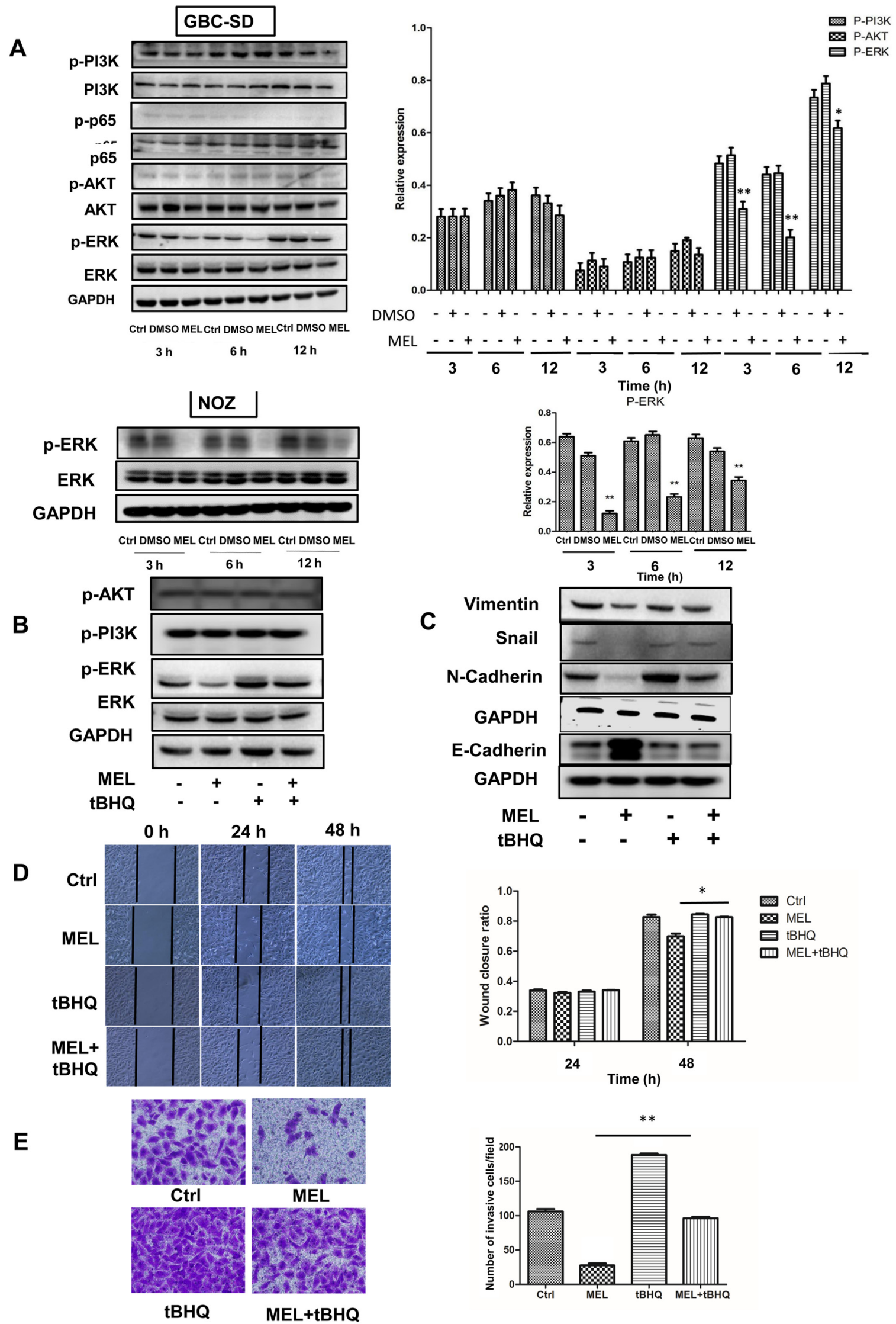

Figure 4. Effects of the ERK signaling pathway on the invasion and epithelial-to-mesenchymal transition of GBC cells. (A) Western blot analysis was performed to detect the protein expression levels of AKT, p-AKT, p65, p-p65, PI3K, p-PI3K, ERK and p-ERK in GBC and NOZ cells treated with melatonin (2 mM) for different time points. (B and C) Western blot analysis was performed to detect the protein expression levels of ERK, p-ERK, N-cadherin, E-cadherin, snail and vimentin in GBC cells following treatment with melatonin and/or tBHQ $(50 \mu \mathrm{M})$ for $48 \mathrm{~h}$. GAPDH was used as the control. (D) The wound healing assay was performed to assess cell migration (magnification $\mathrm{x} 200$ ) following treatment with melatonin and/or tBHQ (50 $\mu \mathrm{M})$ for $48 \mathrm{~h}$. The wound closure rate was analyzed. (E) The Transwell assay was performed to assess cell invasion (magnification x200). Data are presented as the mean $\pm \mathrm{SD}$. ${ }^{*} \mathrm{P}<0.05$; ${ }^{* *} \mathrm{P}<0.01 \mathrm{vs}$. the MEL group. GBC, gallbladder cancer; p, phosphorylated; tBHQ, tert-Butylhydroquinone; MEL, melatonin; Ctrl, control. 
Melatonin inhibits EMT in GBC cells. EMT promotes migration and invasion of human cancer cells (9). Studies have demonstrated that melatonin can downregulate EMT $(9,12)$. Thus, it was speculated that melatonin exerts its inhibitory effect by blocking EMT in gallbladder carcinoma cells. To assess the underlying molecular mechanisms of the antimetastatic effects of melatonin in GBC, cells were treated with $2 \mathrm{mM}$ melatonin for specific time periods. The expression levels of the epithelial marker, E-cadherin, in the melatonin-treated group significantly increased, whereas the expression levels of the mesenchymal phenotype markers, $\mathrm{N}$-cadherin and vimentin, significantly decreased (Fig. 3A). These results were further confirmed via RT-qPCR analysis (Fig. 3B-D). However, the PCR result of Snail was not shown as the gene expression level was much lower compared with the other markers assessed (data not shown). Collectively, these results suggest that melatonin exerts its inhibitory effect by blocking EMT.

Melatonin attenuates EMT and exerts antimetastatic effects by inhibiting the ERK1/2 pathway in GBC cells. Increasing evidence suggest that the AKT, NF- $\mathrm{BB}, \mathrm{PI} 3 \mathrm{~K}, \mathrm{ERK}$ and $\mathrm{Wnt} / \beta$-catenin signaling pathways are involved in the regulation of metastasis caused by melatonin (9). Thus, the present study investigated whether these signaling pathways are involved in melatonin-induced inhibition of GBC-SD cell motility. The results demonstrated that cells treated with melatonin $(2 \mathrm{mM})$ diminished activation of ERK, whereas the phosphorylation levels of AKT, PI3K and NF- $\mathrm{kB}$ were unaffected. To confirm the role of melatonin in downregulating the ERK signaling pathway, NOZ cells were treated with melatonin, and the results demonstrated that the expression of phosphorylated ERK decreased (Fig. 4A). These findings suggest that the ERK signaling pathway may be involved in melatonin-mediated inhibition of GBC cells.

To verify the role of the ERK signaling pathway in regulating the migratory potential and EMT, tBHQ (an activator of ERK1/2) was added to GBC cells (18-20). Notably, tBHQ $(50 \mu \mathrm{M})$ reversed the effects of melatonin in inhibiting phosphorylation of ERK (Fig. 4B). In addition, the expression levels of E-cadherin significantly decreased following treatment with tBHQ, whereas the expression levels of Snail, vimentin and $\mathrm{N}$-cadherin significantly increased compared with cells treated with melatonin (Fig. 4C). Accordingly, the inhibitory effects of melatonin on migration (Fig. 4D) and invasion (Fig. 4E) of GBC cells was partially reversed following treatment with tBHQ. Taken together, these results suggest that melatonin downregulates activity of the ERK signaling pathway, which in turn inhibits EMT and attenuates the metastatic effect observed in GBC cells (Fig. S1).

\section{Discussion}

GBC is the most common malignancy of the biliary tract that exhibits poor prognosis (3). Metastasis remains an important factor that affects the prognosis of patients with GBC (1). Currently, the therapeutic outcome of GBC treatment is extremely poor (21). Melatonin is a naturally occurring hormone secreted by the pineal gland that exhibits anticancer effects on different types of cancer, including glioma, uterine neck, ovarian, colon, liver and lung cancers (12,22-26). Previous studies have demonstrated reduced cytotoxicity of melatonin over a range of doses $(9,26-28)$. The oral administration of $0.5 \mathrm{mg}$ or more of melatonin instantaneously makes itself available in blood plasma, but it does not mimic the endogenous profile (29). However, the effects of melatonin on migration and invasion of GBC cells have not yet been investigated. The results of the present study demonstrated that melatonin inhibited the invasion of GBC cells by blocking activity of the ERK signaling pathway.

To achieve the desired therapeutic effects, endogenous substances are usually administered at considerably high concentrations compared with those corresponding to the physiological levels (30). Melatonin concentrations at $>1 \mu \mathrm{M}$ are described as pharmacological, while the physiological concentrations of this hormone include those $<1 \mathrm{nM}(31,32)$. In the present study, only high concentrations ( 2 and $3 \mathrm{mM}$ ) of melatonin were effective in decreasing GBC cell metastasis. However, treatment of cells with melatonin $(3 \mathrm{mM})$ induced partial apoptosis. Thus, subsequent experiments were performed using $2 \mathrm{mM}$ melatonin. The results of the present study demonstrated that melatonin decreased the invasive and migratory abilities of GBC cells.

EMT is a process during which epithelial cells shift towards the mesenchymal state, which is considered a principal process in tumor metastasis $(33,34)$. The molecular and cellular changes observed in EMT are characterized by upregulation of specific proteins, such as N-cadherin, Snail and vimentin and by downregulation of E-cadherin (35). Thus, these proteins are used as EMT markers. It has been reported that EMT may be associated with the prognosis and clinicopathological characteristics of patients with GBC (36-38). Loss of epithelial markers and dysfunction of EMT-associated transcription factors promotes metastasis of GBC cells $(39,40)$. To further investigate the mechanism of action of melatonin on GBC cells, the expression levels of the EMT-associated markers were assessed in the present study. The results demonstrated that melatonin promoted the expression levels of E-cadherin, while attenuating the levels of $\mathrm{N}$-cadherin, Snail and vimentin. Thus, melatonin may inhibit GBC cell migration and/or invasion by influencing EMT.

Signaling pathways, such as the ERK, NF- $\kappa B$, Wnt, Notch, Hedgehog, activator protein 1 and the growth factor signaling pathways, induce or modulate the EMT process $(9,41)$. Evaluation of the phosphorylated levels of ERK, AKT, p65 and PI3K in the present study demonstrated that only the ERK signaling pathway was inhibited by melatonin. Overactivation of the ERK signaling pathway has been reported in both GBC tissues and cells (42). Melatonin inhibits cancer migration by blocking activation of ERK in different types of human cancer $(11-14,42,43)$. Thus, the present study investigated whether the induction of EMT by melatonin was mediated by regulating the ERK signaling pathway in GBC cells. tBHQ is an ERK activator that induces the phosphorylation of ERK protein (43). The results of the present study demonstrated that the anti-invasive effects of melatonin were reversed by $\mathrm{tBHQ}$, suggesting that this hormone can inhibit EMT via the ERK signaling pathway in GBC cells.

In conclusion, the results of the present study demonstrated that melatonin inhibited the invasion of GBC cells by blocking 
the ERK signaling pathway. This study lays a foundation for future studies investigating the mechanisms of melatonin in GBC and may provide insights into a new therapeutic agent for GBC. However, the lack of further validation in vivo is a limitation of the present study. Further in vivo studies will help to elucidate the role of melatonin in the antitumor therapy of gallbladder cancer.

\section{Acknowledgements}

The authors acknowledge Dr Jianwen Ye (Department of Hepatobiliary and Pancreatic Surgery, The First Affiliated Hospital of Zhengzhou University, Zhengzhou, China) for gifting the NOZ cells.

\section{Funding}

The present study was supported by the National Natural Science Foundation of China (grant. no. 81971881), the Foundation of Henan Charity Federation (grant. no. GDXZ2019002) and the Henan Science and Technology Project (grant. no. SBGJ2020003043).

\section{Availability of data and materials}

All data generated or analyzed during this study are included in this published article.

\section{Authors' contributions}

HWT, XYS and PFZ performed the experiments. WZG, SJZ and JL designed the study. HWT and BY analyzed and interpreted the data. HWT and SJZ wrote the article. HWT, SJZ and XYS confirm the authenticity of all the raw data. All authors have read and approved the final manuscript.

\section{Ethics approval and consent to participate}

Not applicable.

\section{Patient consent for publication}

Not applicable.

\section{Competing interests}

The authors declare that they have no competing interests.

\section{References}

1. Misra S, Chaturvedi A, Misra NC and Sharma ID: Carcinoma of the gallbladder. Lancet Oncol 4: 167-176, 2003.

2. Hundal R and Shaffer EA: Gallbladder cancer: Epidemiology and outcome. Clin Epidemiol 6: 99-109, 2014.

3. Sharma A, Sharma KL, Gupta A, Yadav A and Kumar A: Gallbladder cancer epidemiology, pathogenesis and molecular genetics: Recent update. World J Gastroenterol 23: 3978-3998, 2017

4. Andia ME, Hsing AW, Andreotti G and Ferreccio C: Geographic variation of gallbladder cancer mortality and risk factors in chile: A population-based ecologic study. Int J Cancer 123: 1411-1416, 2008.

5. Sheth S, Bedford A and Chopra S: Primary gallbladder cancer: Recognition of risk factors and the role of prophylactic cholecystectomy. Am J Gastroenterol 95: 1402-1410, 2000.
6. Levy AD, Murakata LA and Rohrmann CA Jr: Gallbladder carcinoma: Radiologic-pathologic correlation. Radiographics 21: 295-314, 2001.

7. Cipolla-Neto J and Amaral FGD: Melatonin as a hormone: New physiological and clinical insights. Endocr Rev 39: 990-1028, 2018.

8. Bhattacharya S, Patel KK, Dehari D, Agrawal AK and Singh S: Melatonin and its ubiquitous anticancer effects. Mol Cell Biochem 462: 133-155, 2019.

9. Su SC, Hsieh MJ, Yang WE, Chung WH, Reiter RJ and Yang SF: Cancer metastasis: Mechanisms of inhibition by melatonin. J Pineal Res 62: 62, 2017.

10. Wei JY, Li WM, Zhou LL, Lu QN and He W: Melatonin induces apoptosis of colorectal cancer cells through HDAC4 nuclear import mediated by CaMKII inactivation. J Pineal Res 58: 429-438, 2015.

11. Mao L, Dauchy RT, Blask DE, Dauchy EM, Slakey LM, Brimer S, Yuan L, Xiang S, Hauch A, Smith K, et al: Melatonin suppression of aerobic glycolysis (Warburg effect), survival signalling and metastasis in human leiomyosarcoma. J Pineal Res 60: 167-177, 2016.

12. Chao CC, Chen PC, Chiou PC, Hsu CJ, Liu PI, Yang YC, Reiter RJ, Yang SF and Tang CH: Melatonin suppresses lung cancer metastasis by inhibition of epithelial-mesenchymal transition through targeting to twist. Clin Sci (Lond) 133: 709-722, 2019.

13. Lin YW, Lee LM, Lee WJ, Chu CY, Tan P, Yang YC, Chen WY, Yang SF, Hsiao M and Chien MH: Melatonin inhibits MMP-9 transactivation and renal cell carcinoma metastasis by suppressing Akt-MAPKs pathway and NF- $\kappa \mathrm{B}$ DNA-binding activity. J Pineal Res 60: 277-290, 2016.

14. Mao L, Summers W, Xiang S, Yuan L, Dauchy RT, Reynolds A, Wren-Dail MA, Pointer D, Frasch T, Blask DE, et al: Melatonin represses metastasis in Her2-postive human breast cancer cells by suppressing RSK2 expression. Mol Cancer Res 14: 1159-1169, 2016.

15. Bubner B and Baldwin IT: Use of real-time PCR for determining copy number and zygosity in transgenic plants. Plant Cell Rep 23: 263-271, 2004

16. Kumar R, Saneja A and Panda AK: An annexin V-FITC-propidium iodide-based method for detecting apoptosis in a non-small cell lung cancer cell line. Methods Mol Biol 2279: 213-223, 2021.

17. Faulstich H,Zobeley S, Rinnerthaler G and Small JV: Fluorescent phallotoxins as probes for filamentous actin. J Muscle Res Cell Motil 9: 370-383, 1988.

18. Hu H, Dong Z, Wang X, Bai L, Lei Q, Yang J, Li L, Li Q, Liu L, Zhang Y, et al: Dehydrocorydaline inhibits cell proliferation, migration and invasion via suppressing MEK $1 / 2-$ ERK1/2 cascade in melanoma. Onco Targets Ther 12: 5163-5175, 2019.

19. Shi H, Bi H, Sun X, Dong H, Jiang Y, Mu H, Liu G, Kong W, Gao R and Su J: Antitumor effects of tubeimoside-1 in NCI-H1299 cells are mediated by microRNA-126-5p-induced inactivation of VEGF-A/VEGFR-2/ERK signaling pathway. Mol Med Rep 17: 4327-4336, 2018.

20. Yu R, Tan TH and Kong AN: Butylated hydroxyanisole and its metabolite tert-butylhydroquinone differentially regulate mitogen-activated protein kinases. The role of oxidative stress in the activation of mitogen-activated protein kinases by phenolic antioxidants. J Biol Chem 14: 28962-28970, 1997.

21. Baiu I and Visser B: Gallbladder cancer. JAMA 320: 1294, 2018.

22. Wang J, Hao H, Yao L, Zhang X, Zhao S, Ling EA, Hao A and Li G: Melatonin suppresses migration and invasion via inhibition of oxidative stress pathway in glioma cells. J Pineal Res 53: 180-187, 2012.

23. Farriol M, Venereo Y, Orta X, Castellanos JM and Segovia-Silvestre T: In vitro effects of melatonin on cell proliferation in a colon adenocarcinoma line. J Appl Toxicol 20: 21-24, 2000.

24. Papazisis KT, Kouretas D, Geromichalos GD, Sivridis E, Tsekreli OK, Dimitriadis KA and Kortsaris AH: Effects of melatonin on proliferation of cancer cell lines. J Pineal Res 25: 211-218, 1998.

25. Petranka J, Baldwin W, Biermann J, Jayadev S, Barrett JC and Murphy E: The oncostatic action of melatonin in an ovarian carcinoma cell line. J Pineal Res 26: 129-136, 1999.

26. Ordoñez R, Carbajo-Pescador S, Prieto-Dominguez N, García-Palomo A, González-Gallego J and Mauriz JL: Inhibition of matrix metalloproteinase-9 and nuclear factor kappa B contribute to melatonin prevention of motility and invasiveness in HepG2 liver cancer cells. J Pineal Res 56: 20-30, 2014.

27. Cutando A, López-Valverde A, Arias-Santiago S, DE Vicente J and DE Diego RG: Role of melatonin in cancer treatment. Anticancer Res 32: 2747-2753, 2012. 
28. Nordlund JJ and Lerner AB: The effects of oral melatonin on skin color and on the release of pituitary hormones. J Clin Endocrinol Metab 45: 768-774, 1977.

29. Malhotra S, Sawhney G and Pandhi P: The therapeutic potential of melatonin: A review of the science. MedGenMed 3: 46, 2004

30. Yerneni LK and Jayaraman S: Pharmacological action of high doses of melatonin on B16 murine melanoma cells depends on cell number at time of exposure. Melanoma Res 13: 113-117, 2003.

31. Dubocovich ML, Delagrange P, Krause DN, Sugden D, Cardinali DP and Olcese J: International union of basic and clinical pharmacology. LXXV. Nomenclature, classification, and pharmacology of $\mathrm{G}$ protein-coupled melatonin receptors. Pharmacol Rev 62: 343-380, 2010.

32. Juszczak M, Roszczyk M, Kowalczyk E and Stempniak B: The influence od melatonin receptors antagonists, luzindole and 4-phenyl-2-propionamidotetralin (4-P-PDOT), on melatonin-dependent vasopressin and adrenocorticotropic hormone $(\mathrm{ACTH})$ release from the rat hypothalamo-hypophysial system. In vitro and in vivo studies. J Physiol Pharmacol 65: 777-784, 2014

33. Baum B, Settleman J and Quinlan MP: Transitions between epithelial and mesenchymal states in development and disease. Semin Cell Dev Biol 19: 294-308, 2008.

34. Chen T, You Y, Jiang H and Wang ZZ: Epithelial-mesenchymal transition (EMT): A biological process in the development, stem cell differentiation, and tumorigenesis. J Cell Physiol 232: 3261-3272, 2017

35. Zeisberg $M$ and Neilson EG: Biomarkers for epithelialmesenchymal transitions. J Clin Invest 119: 1429-1437, 2009.

36. Xu S, Zhan M and Wang J: Epithelial-to-mesenchymal transition in gallbladder cancer: From clinical evidence to cellular regulatory networks. Cell Death Discov 3: 17069, 2017.

37. Puhalla H, Herberger B, Soleiman A, Filipits M, Laengle F, Gruenberger $\mathrm{T}$ and Wrba F: E-cadherin and beta-catenin expression in normal, inflamed and cancerous gallbladder tissue. Anticancer Res 25: 4249-4254, 2005.
38. Kai K, Masuda M and Aishima S: Inverse correlation between $\mathrm{CD} 8^{+}$inflammatory cells and E-cadherin expression in gallbladder cancer: Tissue microarray and imaging analysis. World J Clin Cases 5: 1-8, 2017.

39. Dong P, He XW, Gu J, Wu WG, Li ML, Yang JH, Zhang L, Ding QC, Lu JH, Mu JS, et al: Vimentin significantly promoted gallbladder carcinoma metastasis. Chin Med J (Engl) 124: 4236-4244, 2011

40. Lee DG, Lee SH, Kim JS, Park J, Cho YL, Kim KS, Jo DY, Song IC, Kim N, Yun HJ, et al: Loss of NDRG2 promotes epithelial-mesenchymal transition of gallbladder carcinoma cells through MMP-19-mediated Slug expression. J Hepatol 63: 1429-1439, 2015.

41. Acloque H, Adams MS, Fishwick K, Bronner-Fraser M and Nieto MA: Epithelial-mesenchymal transitions: The importance of changing cell state in development and disease. J Clin Invest 119: 1438-1449, 2009.

42. Buchegger K, Silva R, López J, Ili C, Araya JC, Leal P, Brebi P, Riquelme I and Roa JC: The ERK/MAPK pathway is overexpressed and activated in gallbladder cancer. Pathol Res Pract 213: 476-482, 2017.

43. Lu KH, Su SC, Lin CW, Hsieh YH, Lin YC, Chien MH, Reiter RJ and Yang SF: Melatonin attenuates osteosarcoma cell invasion by suppression of $\mathrm{C}-\mathrm{C}$ motif chemokine ligand 24 through inhibition of the c-Jun N-terminal kinase pathway. J Pineal Res 65: e12507, 2018.

c) (7) $\ominus$ This work is licensed under a Creative Common International (CC BY-NC-ND 4.0) License. 